\title{
Suboptimal CPAP adherence: half a loaf is better than no bread at all
}

\author{
Martha E. Billings ${ }^{1}$, Patrick Lévy ${ }^{2}$ and Najib Ayas ${ }^{3}$ \\ Affiliations: ${ }^{1}$ Division of Pulmonary, Critical Care and Sleep Medicine, Dept of Medicine, University of \\ Washington School of Medicine, Seattle, WA, USA. ${ }^{2}$ Grenoble Alpes University, Grenoble, France. ${ }^{3}$ Division of
} Critical Care Medicine, University of British Columbia, Vancouver, BC, Canada.

Correspondence: Martha E. Billings, Box 359803, UW Medicine Sleep Center, Harborview Medical Center, 325 Ninth Avenue, Seattle, WA 98104, USA. E-mail: mebillinduw.edu

@ERSpublications

Suboptimal CPAP use, less than $4 \mathrm{~h}$ per night, may still have beneficial effects on daytime sleepiness. Removing CPAP in those who routinely use it for 2-3 h a night worsened their daytime sleepiness. http://bit.ly/36FjnF6

Cite this article as: Billings ME, Lévy P, Ayas N. Suboptimal CPAP adherence: half a loaf is better than no bread at all. Eur Respir J 2020; 55: 2000144 [https://doi.org/10.1183/13993003.00144-2020].

Positive airway pressure (PAP) is the most effective therapy for obstructive sleep apnoea (OSA), a condition affecting an estimated 936 million adults worldwide [1]. Adequate PAP adherence has been defined as $4 \mathrm{~h}$ of average use in most research studies. Many US insurance carriers and national payers, including the Centers for Medicaid and Medicare Services (CMS), determine coverage of PAP and supplies based on this metric. If Medicare patients do not meet the threshold of $4 \mathrm{~h}$ per night for $70 \%$ of nights, their PAP may be confiscated in the USA [2]. This policy may have detrimental consequences for Medicare beneficiaries with OSA [3]. In France, however, a 3-h average use is required for PAP coverage, established more than 20 years ago as a legal minimal usage not corresponding to any physiological threshold. Suboptimal adherence to PAP is exceptionally common, with only $\sim 50 \%$ using PAP $>4$ h per night at 1 year in most trials [4-6]. PAP adherence may considerably vary from one country to another with improved global management of the disease [7]. Additionally, differences in adherence inconsistently correlate with baseline symptoms of sleepiness, or OSA severity; many subjective benefits of PAP similarly do not correspond in a clear dose-dependent fashion [8-11].

In this issue of the European Respiratory Journal, GAISL et al. [12] take on the concept of inadequate PAP adherence and assess if even suboptimal use has benefit. This was an elegant study design using a PAP withdrawal technique in the context of a double-blinded randomised controlled trial. Eligible subjects had moderate to severe sleep apnoea ( $4 \%$ oxygen desaturation index $\geqslant 15$ per $\mathrm{h}$ ), pre-treatment Epworth Sleepiness Scale $(E S S)>10$, and had been treated with PAP for at least 12 months with a residual apnoeahypopnoea index (AHI) $<10$ per $\mathrm{h}$, and with suboptimal adherence (mean usage $3-4 \mathrm{~h}$ per night). Patients were then randomised to a therapeutic PAP device, or a sham PAP device. The sham device appears identical to active PAP but does not deliver a therapeutic pressure so that patient blinding can be maintained. The AHI on sham therapy was a mean of 34 per $\mathrm{h}$ compared to 3.6 per $\mathrm{h}$ in the active PAP group. Patient survey responses support that they remained blinded to treatment allocation, despite greater use of PAP in the active compared to sham group.

The results were quite striking; in the sham group, ESS increased by 2.0 (from 8.3 to $10.3 ; \mathrm{p}=0.02$ ) while ESS decreased in the therapeutic group (from 8.7 to 8.2) with a significant difference between the groups (difference in ESS=2.4; $\mathrm{p}=0.01$ ). As pointed out by the authors, this degree of ESS change is similar to the 
improvement in ESS upon treatment with PAP in patients with OSA in recent meta-analyses [13, 14] and is thus clinically significant; this minimal clinically important difference (MCID) has been adopted by the National Institute for Health and Care Excellence (NICE) in the UK as economically significant and 2.0 was established as MCID in OSA $[15,16]$. Sleep-related quality of life measured by the FOSQ-10 was also significantly worsened in the sham group. Objective measures of sleepiness (i.e. OSLER and MURT tests assessing attention and reaction time) and other secondary outcomes such as blood pressure and quality of life measured by the SF-36 were not statistically different by treatment allocation but tended to worsen in the sham group. Thus overall, with removal of "partial" PAP therapy, those in the sham group had deterioration in sleepiness and some functional outcomes.

Notably, mean PAP adherence increased in the therapeutic group (from 3.1 to $4.6 \mathrm{~h}$ ), with $66 \%$ of these subjects previously with "suboptimal adherence" now meeting adherence thresholds during the trial. This may be due to patients' awareness of being monitored in the context of the trial (Hawthorne effect) [17], although certainly many PAP trials do not show enhanced adherence. Conversely, adherence fell sharply in those randomised to sham devices (mean of 3.5 to $2.1 \mathrm{~h}$ per night), despite also being monitored in the trial. The reasons for this are unclear. One possibility is that some patients may have recognised, possibly subconsciously, that they were receiving sham therapy. The ability to truly blind patients with sub-therapeutic pressure devices could be questioned, especially given individuals had previously experienced therapeutic PAP pressures for a year. However, only $59 \%$ of patients in the study were able to correctly guess their correct allocation, suggesting that patient blinding was reasonable.

Trial patients also notoriously have poor PAP adherence (in the SAVE trial, average of $3.3 \mathrm{~h}$ per night) [18] compared to recent "real world" big data gathered from large samples of modern PAP devices, (average $5.1 \mathrm{~h}$ per night in the ResMed study of 2.6 million patients worldwide) [7]. Adherence to treatment in the real-world may be due to improvement in devices and masks, appropriate support when initiating the treatment and adequate medical and technical follow-up via telehealth [19, 20]. Also, symptom improvement and side-effect perception may be critical. Thus, the previous perception of widespread poor PAP adherence may be no longer accurate and limited to the artificial trial setting. The subjects in this trial were selected with 1 year of "real-world" sub-optimal adherence data, suggesting that the participation in a trial was not a strong driver of use.

Strengths of the study included the multi-site nature and use of sham devices as placebo. However, there were several limitations. The sample size was relatively small and might have limited the ability to detect changes in secondary outcomes. The ability to truly blind patients to therapy could also be an issue. The patients studied were carefully selected and results might not be extrapolated to all patients with OSA using PAP for 3-4 h per night. That is, these patients had at least moderate disease and were sleepy at baseline. In addition, the patients had to persist with suboptimal usage for at least 12 months; many patients with suboptimal usage in the short term (e.g. after 1-2 months) may discontinue the device. One might surmise that, given their continued PAP, they were a subgroup experiencing benefit with even low durations of PAP use. The reduction in ESS from diagnosis to study entry also supports this benefit.

Nevertheless, we believe this study shows that there are clearly patients who benefit symptomatically from PAP treatment even if their use is under the 4-h threshold for adherence. These patients had a clinically significant worsened daytime sleepiness when placed on sham PAP. This is also consistent with anecdotal experience by many sleep clinicians, including our own observations that many patients derive benefit from PAP who do not technically meet adherence requirements. Therefore, the definition of "adherence" set at $4 \mathrm{~h}$ should be re-examined, as this lower use still has therapeutic benefit for many. Additionally, sleep itself is heterogeneous with likely different severity of OSA and PAP efficacy depending on the timing of use and sleep stage, such as during REM, when OSA is much more severe, with possibly greater cardiovascular consequences [21]. $4 \mathrm{~h}$ of use at the start of the night during $\mathrm{N} 2 / \mathrm{N} 3$ sleep may have the same subjective benefit as just $2 \mathrm{~h}$ of use during a period of intense REM sleep in the early morning hours. PAP adherence should be less defined by duration of use per night when benefit may be linked with appropriately timed sleep, duration of sleep and sleep stage specific use. In light of the finding in this study and others, the strict 4-h use policy for PAP coverage in the USA should be revisited. The optimal threshold for adequate nightly use may depend upon patient goals. Normalisation of daytime sleepiness, quality of life, and neurocognitive function generally improve with more hours of use [22]. Stroke, atrial fibrillation risk reduction may be greater in those using PAP for more than $4 \mathrm{~h}[23,24]$, although this remains controversial as only post hoc analyses support this in larger randomised controlled trials [18, 25-27]. Thus, it seems arbitrary to designate $4 \mathrm{~h}$ of use as a requirement for PAP adherence and coverage decisions when this metric has insufficient clinical data. 


\section{References}

1 Benjafield AV, Ayas NT, Eastwood PR, et al. Estimation of the global prevalence and burden of obstructive sleep apnoea: a literature-based analysis. Lancet Respir Med 2019; 7: 687-698.

2 US Centers for Medicare and Medicaid Services. Positive Airway Pressure (PAP) Devices: Complying with Documentation \& Coverage Requirements. 2016. www.cms.gov/Outreach-and-Education/Medicare-LearningNetwork-MLN/MLNProducts/downloads/PAP_DocCvg_Factsheet_ICN905064.pdf

3 Naik S, Al-Halawani M, Kreinin I, et al. Centers for Medicare and Medicaid Services positive airway pressure adherence criteria may limit treatment to many Medicare beneficiaries. J Clin Sleep Med 2019; 15: 245-251.

4 Chai-Coetzer CL, Luo YM, Antic NA, et al. Predictors of long-term adherence to continuous positive airway pressure therapy in patients with obstructive sleep apnea and cardiovascular disease in the SAVE study. Sleep 2013; 36: 1929-1937.

5 Baratta F, Pastori D, Bucci T, et al. Long-term prediction of adherence to continuous positive air pressure therapy for the treatment of moderate/severe obstructive sleep apnea syndrome. Sleep Med 2018; 43: 66-70.

6 Weaver TE, Grunstein RR. Adherence to continuous positive airway pressure therapy: the challenge to effective treatment. Proc Am Thorac Soc 2008; 5: 173-178.

7 Cistulli PA, Armitstead J, Pepin JL, et al. Short-term CPAP adherence in obstructive sleep apnea: a big data analysis using real world data. Sleep Med 2019; 59: 114-116.

8 May AM, Gharibeh T, Wang L, et al. CPAP Adherence predictors in a randomized trial of moderate-to-severe OSA enriched with women and minorities. Chest 2018; 154: 567-578.

9 Wohlgemuth WK, Chirinos DA, Domingo S, et al. Attempters, adherers, and non-adherers: latent profile analysis of CPAP use with correlates. Sleep Med 2015; 16: 336-342.

10 Mehrtash M, Bakker JP, Ayas N. Predictors of continuous positive airway pressure adherence in patients with obstructive sleep apnea. Lung 2019; 197: 115-121.

11 Weaver TE, Mancini C, Maislin G, et al. Continuous positive airway pressure treatment of sleepy patients with milder obstructive sleep apnea: results of the CPAP Apnea Trial North American Program (CATNAP) randomized clinical trial. Am J Respir Crit Care Med 2012; 186: 677-683.

12 Gaisl T, Rejmer P, Thiel S, et al. Effects of suboptimal adherence of CPAP therapy on symptoms of obstructive sleep apnoea: a randomised, double-blind, controlled trial. Eur Respir J 2020; 55: 1901526.

13 Bratton DJ, Gaisl T, Schlatzer C, et al. Comparison of the effects of continuous positive airway pressure and mandibular advancement devices on sleepiness in patients with obstructive sleep apnoea: a network meta-analysis. Lancet Respir Med 2015; 3: 869-878.

14 Giles TL, Lasserson TJ, Smith B, et al. Continuous positive airways pressure for obstructive sleep apnoea in adults. Cochrane Database Syst Rev 2006; CD001106.

15 Patel S, Kon SSC, Nolan CM, et al. The Epworth Sleepiness Scale: minimum clinically important difference in obstructive sleep apnea. Am J Respir Crit Care Med 2018; 197: 961-963.

16 McDaid C, Griffin S, Weatherly $\mathrm{H}$, et al. Continuous positive airway pressure devices for the treatment of obstructive sleep apnoea-hypopnoea syndrome: a systematic review and economic analysis. Health Technol Assess 2009; 13: iii-iv, xi-xiv, 1-119, 143-274.

17 Sedgwick P, Greenwood N. Understanding the Hawthorne effect. BMJ 2015; 351: h4672.

18 McEvoy RD, Antic NA, Heeley E, et al. CPAP for prevention of cardiovascular events in obstructive sleep apnea. N Engl J Med 2016; 375: 919-931.

19 Hwang D, Chang JW, Benjafield AV, et al. Effect of telemedicine education and telemonitoring on continuous positive airway pressure adherence. The Tele-OSA randomized trial. Am J Respir Crit Care Med 2018; 197: $117-126$.

20 Malhotra A, Crocker ME, Willes L, et al. Patient engagement using new technology to improve adherence to positive airway pressure therapy: a retrospective analysis. Chest 2018; 153: 843-850.

21 Aurora RN, Crainiceanu C, Gottlieb DJ, et al. Obstructive sleep apnea during REM sleep and cardiovascular disease. Am J Respir Crit Care Med 2018; 197: 653-660.

22 Antic NA, Catcheside P, Buchan C, et al. The effect of CPAP in normalizing daytime sleepiness, quality of life, and neurocognitive function in patients with moderate to severe OSA. Sleep 2011; 34: 111-119.

23 Gupta A, Shukla G, Afsar M, et al. Role of positive airway pressure therapy for obstructive sleep apnea in patients with stroke: a randomized controlled trial. J Clin Sleep Med 2018; 14: 511-521.

24 Qureshi WT, Nasir UB, Alqalyoobi S, et al. Meta-analysis of continuous positive airway pressure as a therapy of atrial fibrillation in obstructive sleep apnea. Am J Cardiol 2015; 116: 1767-1773.

$25 \mathrm{Yu}$ J, Zhou Z, McEvoy RD, et al. Association of positive airway pressure with cardiovascular events and death in adults with sleep apnea: a systematic review and meta-analysis. JAMA 2017; 318: 156-166.

26 Peker Y, Glantz H, Eulenburg C, et al. Effect of positive airway pressure on cardiovascular outcomes in coronary artery disease patients with nonsleepy obstructive sleep apnea. The RICCADSA randomized controlled trial. Am J Respir Crit Care Med 2016; 194: 613-620.

27 Shaw JE, Punjabi NM, Naughton MT, et al. The effect of treatment of obstructive sleep apnea on glycemic control in type 2 diabetes. Am J Respir Crit Care Med 2016; 194: 486-492. 